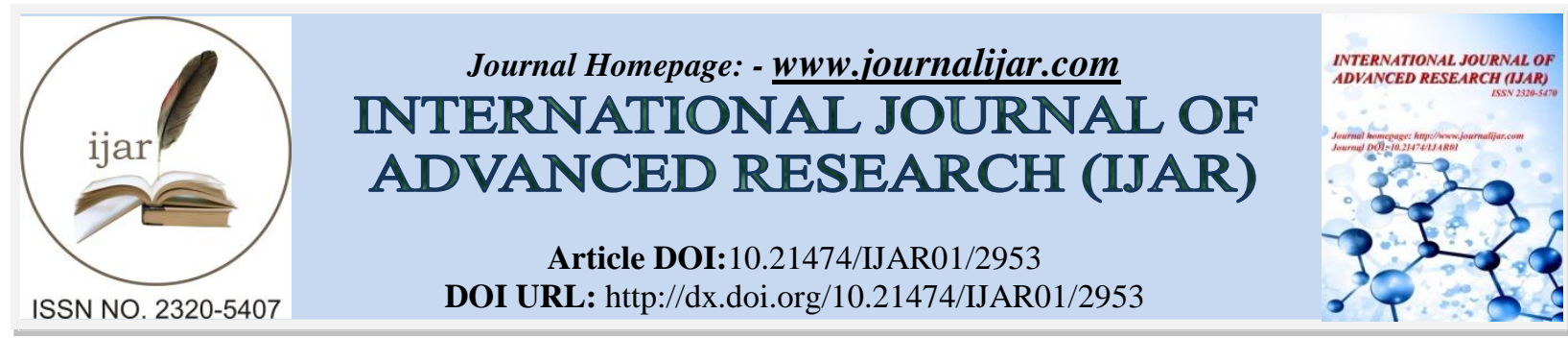

RESEARCH ARTICLE

\title{
PROSPECTIVE STUDY OF RESPIRATORY TRACT INFECTION AMONG PILGRIMS VISITING ER AT ALMADINAHALMONAWARRH , 2016.
}

\section{Yousef AbdulazizEkhmimi, Wala'a AbdulmalikAlraddadi, Abdullah Hasan Alhojaili, Bashaer AbdulfattahAlrehaili, Mohammed MuznAlharbi, Afnan Ahmed Alfraidy, Mohammed A Kareem and Alhassan Ali Alghamdi.}

Kingdom of Saudi Arabia, Taibah University, College of medicine.

\section{Manuscript Info}

\section{Manuscript History}

Received: 29 November 2016

Final Accepted: 26 December 2016

Published: January 2017

\section{Abstract}

Objectives: To compare the differences between the incidence of respiratory tract infections before and after performing Hajj and to identify the risk factors that may increase the prevalence of respiratory tract infections during Hajj.Methods: During the Hajj season of $1437 \mathrm{H}$ in $\mathrm{Al}$ Madinah, a prospective cohort study consisting of 566 pilgrim patients was admitted to ER in King Fahad Hospital (160 patients), Al Anssar (100), Bab Jebril Primary Health Clinic (70) and Al Safiah Primary Health Care (236). A face-to-face semi-structured questionnaire was given to each participant a week before and after the Hajj.

Results: During the two-week examination period, $92 \%$ of patients suffered from respiratory symptoms. It was the first visit to the doctor with the same symptoms for $82.3 \%$ of pilgrims. The age group of a vast majority of the patients who participate in the study was 46-65 years. Findings indicate that $89.2 \%$ of participants had been in crowded places during the pilgrimage period. Also, $15.9 \%$ of participants were smokers, and $81.3 \%$ of them had a good ventilation in their residential places. The residential areas of participants (63.4\%) were very far from any sources of air pollution. Besides, $82.2 \%$ of them did not use their personal belongings during the pilgrimage period..

Conclusion: Most pilgrim patients suffered from and shown respiratory symptoms during Hajj. The study noted a reduction in most risk factors which increase respiratory tract infections except the problem of overcrowding during the Hajj season, a problem that cannot be avoided during the pilgrimage to Makkah Al Mukarramah and Al Madinah Al Munawarah, Saudi Arabia.

Copy Right, IJAR, 2016,. All rights reserved.

Abbreviations Table:-

\begin{tabular}{|l|l|}
\hline Abbreviation & Description \\
\hline ER & emergency room \\
\hline URTI & upper respiratory tract infections \\
\hline
\end{tabular}




\section{Introduction:-}

\section{Rationale and significance:=}

The Islamic pilgrimage is unarguably the largest crowded event in the world. As at today, about two million pilgrims from more than 180 countries gather annually for Hajj to the holy cities of Makkah Al Mukarramah and Al Madinah Al Munawarah, Saudi Arabia. During this annual gathering, pilgrims are usually in close contact with one another, especially during Tawaf. As a result, this holy assembly usually exposes religious travellers to a high risk of infectious diseases, especially acute respiratory tract infections. (1) Evidence from the literature has also showed that pilgrims suffer from common infectious diseases such as common cold and other ailments such as influenza and pneumonia, both of which may lead to many complications and thus require urgent medical attentions. (2)

Furthermore, the congregation of such large number of pilgrims may present many public health risks and challenges. (3) In other words, the gathering in populous and limited places for a short time amplifies health risks and hazards. Physical exertion, overcrowding and any existing medical conditions such as diabetes mellitus and cardiovascular illness increase the chance of acquiring infectious diseases among pilgrims. (4)

The demographic characteristics of patients in the previous studies showed that cases of respiratory infections in males $(43.5 \%)$ were higher than those of females (33.5\%). According to the age demographic breakdown of participants, the elderly group (more than 50 years) were involved in more than $94 \%$ of cases. Put simply, elderly people are more prone to infectious disease due to the disruption of diets and sleep and the impairment of the immune system. As for the nationality, most cases of infectious diseases were traced to Indonesian pilgrims (18\%), Saudis (17\%) and Pakistani (11\%) pilgrims (4).

Many previous studies about respiratory tract infections found that cases of such infections increased during Hajj. Although an infection in the upper respiratory tract is very common, lower respiratory tract infection (pneumonia) can occur, and the latter is much more deadly than the former. The leading cause of these ailments includes influenza virus, other viruses and bacteria.

An increase in the incidence of respiratory tract infection during Hajj has a serious impact on the general health of the population as it could lead to an epidemic infection and have adverse effects on the economic by increasing healthcare costs and hospital bed demands as well as contributing to the loss of workdays. The purpose of this study is to compare the differences between the incidence of chest infection before and after performing Hajj and to proffer solutions and identify the risk factors that may increase the prevalence of such infection during Hajj.

1.2. Specific objectives:

- To compare the differences between the incidence of respiratory tract infections before and after performing Hajj.

- To identify the risk factors that may increase the prevalence of respiratory tract infection during Hajj.

\section{Methodology:-}

During the Hajj season of $1437 \mathrm{H}$ in Al Madinah, a prospective cohort study had been conducted a week before and after the pilgrimage. Data were collected using face-to-face semi-structured questionnaire from patients in King Fahad Hospital (160 patients), Al Anssar (100), Bab Jebril Primary Health Clinic (70) and Al Safiah Primary Health Care (236).

The interviewed was developed based on the literature, sociodemographic data, common respiratory complaints that brought pilgrims to ER, related risk factor and medication. The inclusion criteria were nasal discharge and congestion, cough, sneezing, sore throat, pleuritic chest pain and fever. The data were consequently entered into a portable computer file of access program, and the statistical analysis was done using SPSS version 20.

\section{Population \& Sample of the Study:-}

The study population included all pilgrims of $1437 \mathrm{H}$ who were treated in one of the hospitals designated to receive them. As a result of the exposure to respiratory diseases before or after performing the pilgrimage, a random sample of 566 patients was selected. The participants were interviewed, and a questionnaire was given to each of them. Table 1 shows the characteristics of the participants according to their personal data. 
Table (1):- The participants personal data.

\begin{tabular}{|c|c|c|c|}
\hline \multicolumn{2}{|l|}{ Personal Data } & $\# \quad(\%)$ & $P$-value \\
\hline \multirow{2}{*}{ Gender } & Male & 405 (71.6) & \multirow{2}{*}{$0.00 * *$} \\
\hline & Female & $161(28.4)$ & \\
\hline \multirow{6}{*}{ Age } & 25 or less & $11(1.9)$ & \multirow{6}{*}{$0.00 * *$} \\
\hline & $26-35$ & $71 \quad(12.5)$ & \\
\hline & $36-45$ & $134(23.7)$ & \\
\hline & $46-55$ & $143(25.3)$ & \\
\hline & $56-65$ & $152(26.9)$ & \\
\hline & 66 and more & $55(9.7)$ & \\
\hline \multirow{4}{*}{ Marital status } & Single & $29 \quad(5.1)$ & \multirow{4}{*}{$0.00 * *$} \\
\hline & Married & $508(89.8)$ & \\
\hline & Divorced & $6 \quad(1.1)$ & \\
\hline & Widower & $23(4.1)$ & \\
\hline \multirow{2}{*}{ Nationality } & Saudi & $\begin{array}{ll}0 & (0.0) \\
\end{array}$ & \multirow{2}{*}{--} \\
\hline & Non-Saudi & $566(100.0)$ & \\
\hline \multirow{4}{*}{ Education level } & Illiterate & $147(26.0)$ & \multirow{4}{*}{$0.00 * *$} \\
\hline & secondary & $194(34.3)$ & \\
\hline & Bachelor & $193(34.1)$ & \\
\hline & Master / PhD & $32 \quad(5.7)$ & \\
\hline \multirow{3}{*}{ Monthly income } & less than $2500 \mathrm{sr}$ & $370(65.4)$ & \multirow{3}{*}{$0.00 * *$} \\
\hline & $3000-5000 \mathrm{sr}$ & $156(27.6)$ & \\
\hline & More than $5000 \mathrm{sr}$ & $40 \quad(7.1)$ & \\
\hline
\end{tabular}

**Chi Square test - Significant at the 0.01 level.

As shown in Table 1, $71.6 \%$ of the participants were males, and $28.6 \%$ of them were females. Based on the distribution of their ages, some participants were 56-65 years old (26.9\%), 46-55 years old (25.3\%), 36-45 years old (23.7\%), 26 -35 years old (12.5\% ), more than 66 years old (9.7\%), and less than 25 years old $(1.9 \%)$.

As for the demographic of marital status, A number of sample members were married (89.8\%), singles (5.1\%), widows $(4.1 \%)$, and divorced (1.1\%).

The participants' distribution according to their educational level was as follows; $26 \%$ of them were illiterates, $34.3 \%$ had secondary school certificates, and $34.1 \%$ had bachelor degrees, and $5.7 \%$ were postgraduates. Lastly, their distribution according to their monthly income was as follows: $65.4 \%$ of the participants earned less than 2500 SAR, 27.6\% received 3000-5000 SAR, and 7.1\% were paid more than 50, 000 SAR. The personal diagram of participants is shown below (see Figure 1): 


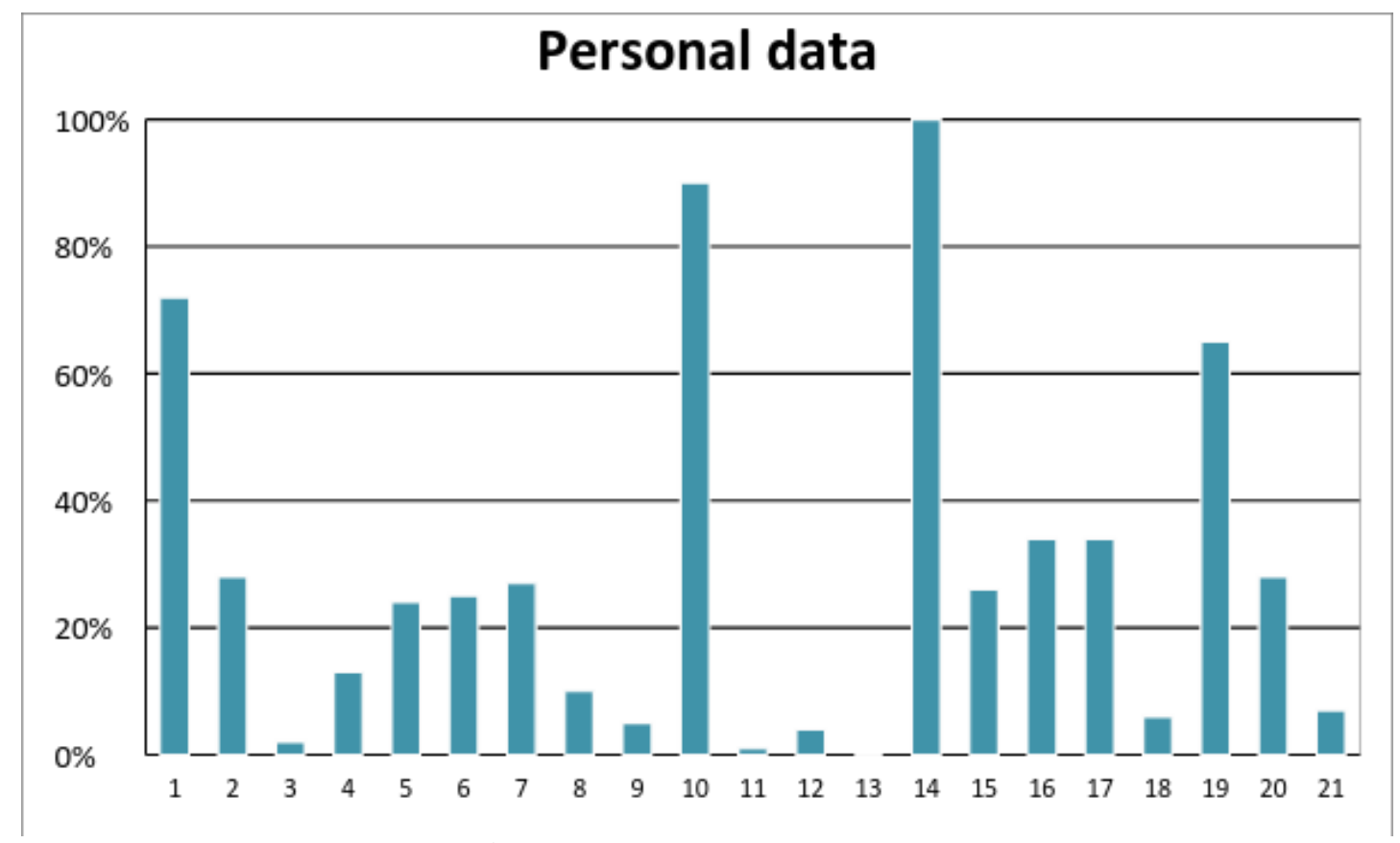

Graph (1)-: The participants personal data.

\section{Results:-}

Table 2 shows the participants' distribution based on whether they were suffering from symptoms of the respiratory system; $92 \%$ of them suffered from the symptoms of the respiratory system, while $8 \%$ did not show any of sign of respiratory disorder.

Table (2):- Shows the participants' distribution according to whether they were suffering from symptoms of the respiratory system.

\begin{tabular}{|l|l|l|}
\hline Answer & Frequency & Percent \\
\hline Yes & 521 & 92.0 \\
\hline No & 45 & 8.0 \\
\hline Total & 566 & 100.0 \\
\hline
\end{tabular}

The following diagram highlights some of the disease symptoms experienced by the participants and the proportions of each of them. As indicated in Figure 2, 32\% suffered from flu, 23\% had a sore throat, $13 \%$ were vulnerable to dry cough, $10 \%$ were susceptible to dry cough, $6 \%$ had a high temperature, and 5\% suffered from chest pain. 


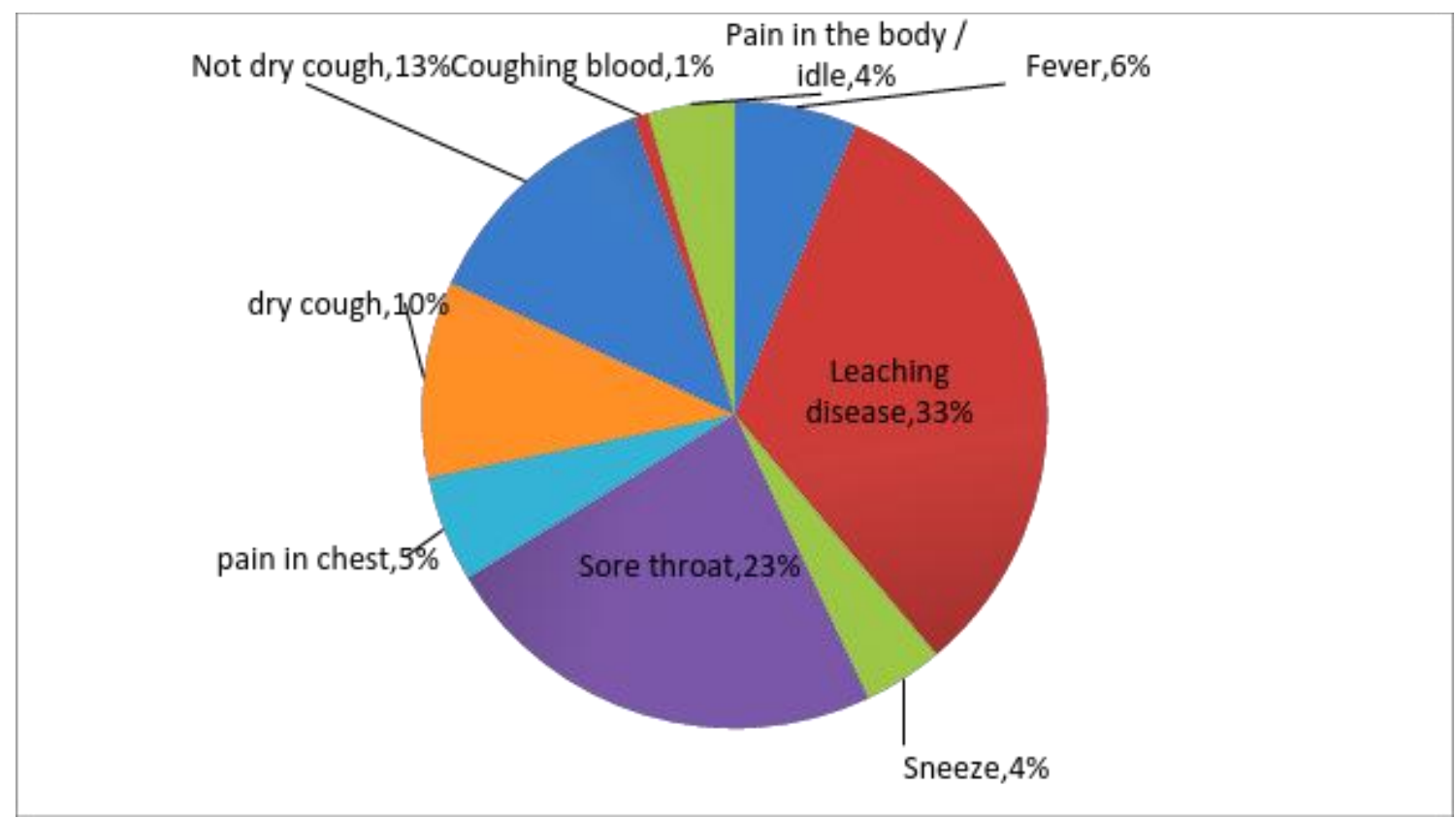

Graph (2): Shows some of the disease symptoms experienced by the participants in the study.

The next table indicates the participants' distribution according to whether they had been in crowded places during the pilgrimage period. As depicted in Table 3, unlike $89.2 \%$ of them, $10.8 \%$ were not crowded places during the pilgrimage period.

Table (3):- Shows the participants' distribution according to whether they had been in crowded places during the pilgrimage period.

\begin{tabular}{|l|l|l|}
\hline Answer & Frequency & Percent \\
\hline Yes & 505 & 89.2 \\
\hline No & 61 & 10.8 \\
\hline Total & 566 & 100.0 \\
\hline
\end{tabular}

Table 4 shows the participants' distribution according to whether they utilised their personal belongings (towels, pillow, eating utensils, etc.) during the pilgrimage period; on one hand, $82.2 \%$ of them did not use their personal belongings during the pilgrimage period; on the other hand, $17.8 \%$ utilized their personal belongings during Hajj.

Table (4):- Shows the participants 'distribution according to whether they participated their personal belongings during the pilgrimage period.

\begin{tabular}{|l|l|l|}
\hline Answer & Frequency & Percent \\
\hline Yes & 101 & 17.8 \\
\hline No & 465 & 82.2 \\
\hline Total & 566 & 100.0 \\
\hline
\end{tabular}

The following diagram shows the means of transportation used by the participants to navigate to Medina. As shown in Figure 3, some participants used planes (49\%), buses (35\%), cars (8\%), and ships (8\%). 


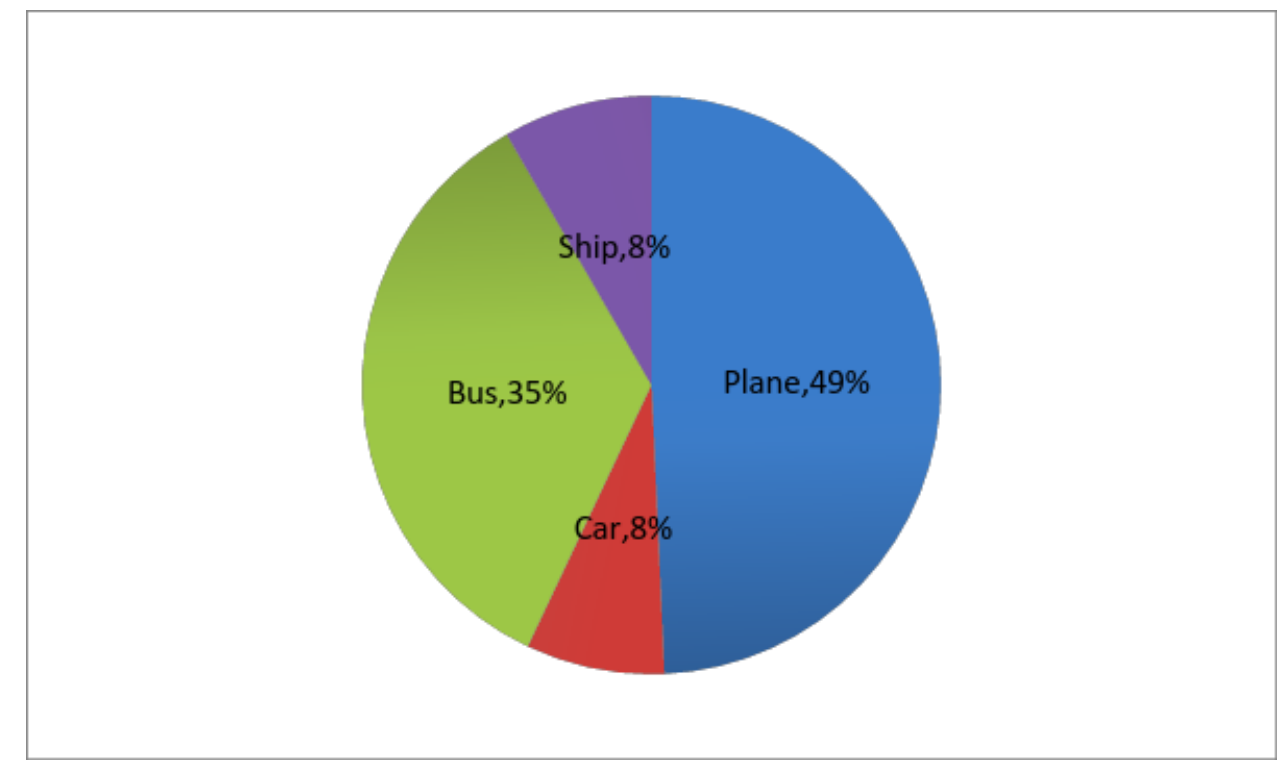

Graph (3): Shows the means of transportation used by the participants during their journey to get to Medina.

The next table shows some of the diseases that were suffered by the participants and proportions of each; $35.7 \%$ suffered from diabetes, $36 \%$ of them suffered from hypertension, $13.8 \%$ of them suffered from asthma, $1.4 \%$ of them suffered from immune diseases, and other diseases by $13.1 \%$.

Table (5):Diseases suffered by the participants..

\begin{tabular}{|l|l|l|}
\hline Answer & Frequency & Percent \\
\hline diabetes & 106 & $35.69 \%$ \\
\hline hypertension & 107 & $36.03 \%$ \\
\hline asthma & 41 & $13.80 \%$ \\
\hline immune diseases & 4 & $1.35 \%$ \\
\hline Others & 39 & $13.13 \%$ \\
\hline
\end{tabular}

Based on whether they have had an organ transfer process before, $99.8 \%$ of them have never had a transfer process, whereas only $0.2 \%$ of them have done so (see Table 6).

Table (6): Participants distribution according to whether they have had an organ transfer process before.

\begin{tabular}{|l|l|l|}
\hline Answer & Frequency & Percent \\
\hline Yes & 1 & .2 \\
\hline No & 565 & 99.8 \\
\hline Total & 566 & 100.0 \\
\hline
\end{tabular}

The next table shows some of the medicines used by the participants and the proportion of each medication. As illustrated in Table 7, a number of participants used analgesics (35.3\%), 10.7\% for steroids (10.7\%), chemotherapy $(4.3 \%)$, antidepressants $(4.3 \%)$, antibiotics $(2.7 \%)$, and other medicines $(42.8 \%)$.

Table (7):Medications used by participants.

\begin{tabular}{|l|l|l|}
\hline Answer & Frequency & Percent \\
\hline steroids & 20 & 10.7 \\
\hline antibiotics & 5 & 2.7 \\
\hline chemotherapy & 8 & 4.3 \\
\hline antidepressants & 8 & 4.3 \\
\hline analgesics & 66 & 35.3 \\
\hline Others & 80 & 42.8 \\
\hline
\end{tabular}

The next table shows the participants' distribution concerning smoking. As shown in Table $8,84.1 \%$ of them were non-smokers and $15.9 \%$ were non-smokers.

Table (8): Participants' distribution concerning smoking.

\begin{tabular}{|l|l|l|}
\hline Answer & Frequency & Percent \\
\hline
\end{tabular}




\begin{tabular}{|l|l|l|}
\hline Yes & 90 & 15.9 \\
\hline No & 476 & 84.1 \\
\hline Total & 566 & 100.0 \\
\hline
\end{tabular}

The following diagram shows the distribution sample of ers according to the period which they spent smoking. As indicated in Figure 4, some patients smoked for less than 10 years (23.3\% ), 10-20 years (42.2\%), and more than 20years $(34.5 \%)$.

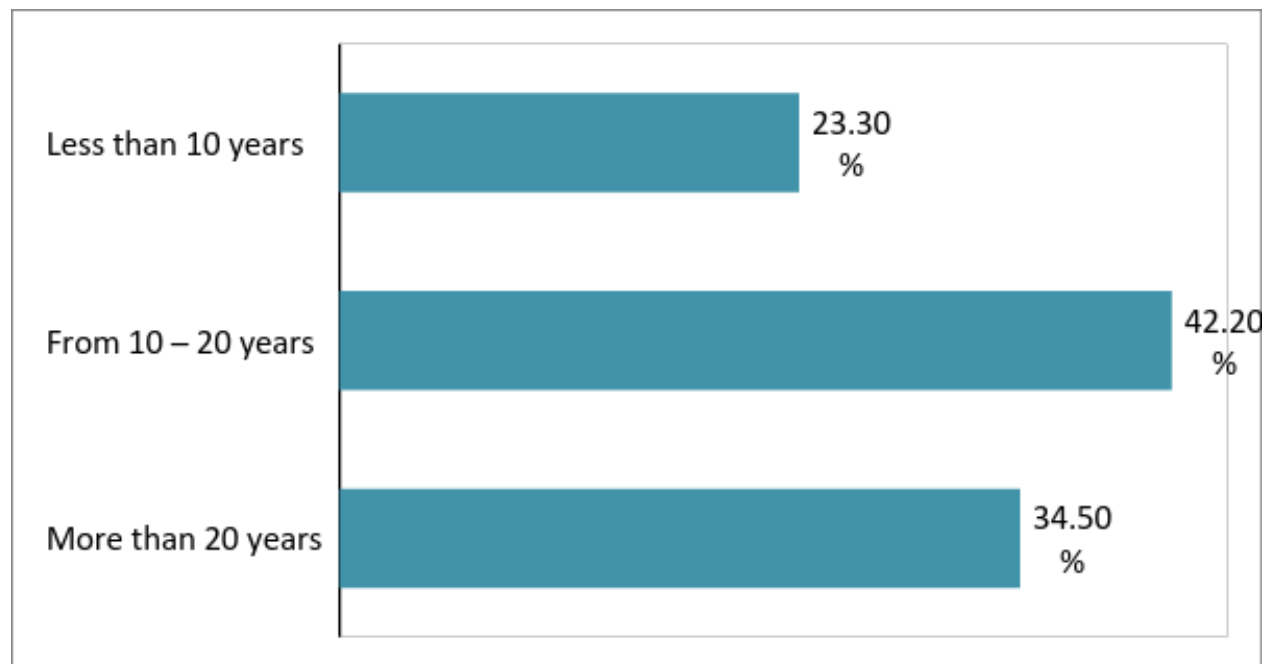

Graph (4): Shows the distribution of smokers according to the period of time they spent in smoking.

Table 9 explains the participants' distribution regarding whether the ventilation was good in their place of residence during the pilgrimage period; $81.3 \%$ of them had a good ventilation in their place of residence, while $18.7 \%$ did not have such semblance of atmosphere

Table (9):-Table 9: Participants' distribution regarding whether theventilation was good in their place of residence during the pilgrimage period.

\begin{tabular}{|l|l|l|}
\hline Answer & Frequency & Percent \\
\hline Yes & 460 & 81.3 \\
\hline No & 106 & 18.7 \\
\hline Total & 566 & 100.0 \\
\hline
\end{tabular}

The next table also shows the participants' distribution in terms of whether their place of residence close to any air pollution such as traffic jam or torched places... etc., during the period of pilgrimage; $63.4 \%$ of them said that their residence places weren't close to any air pollution sources, while $36.6 \%$ said that their residence places were close to the air pollution.

Table (10):- shows the participants' distribution in terms of whether their place of residence close to any air pollution during the period of pilgrimage

\begin{tabular}{|l|l|l|}
\hline Answer & Frequency & Percent \\
\hline Yes & 207 & 36.6 \\
\hline No & 359 & 63.4 \\
\hline Total & 566 & 100.0 \\
\hline
\end{tabular}

The next table shows the participants' distribution regarding whether this meeting was their first visits to the doctor with the same symptoms. As shown in Table 11, 82.3\% of participants maintained that this meeting was their first visits to the doctor with the same symptoms. On the other hand, $17.7 \%$ of them pointed out that this meeting was not their first visit to the doctor with the same symptoms. 
Table (11):-Participants' distribution regarding whether this meeting was their first visits to the doctor with the same symptoms.

\begin{tabular}{|l|l|l|}
\hline Answer & Frequency & Percent \\
\hline Yes & 466 & 82.3 \\
\hline No & 100 & 17.7 \\
\hline Total & 566 & 100.0 \\
\hline
\end{tabular}

Table 11 indicates the number of times the participants, who have had several visits to the doctor with the same symptoms, visited the doctor with the same symptoms; $45 \%$ of them visited a doctor once before this visit, $39 \%$ visited a doctor twice for the same symptoms prior to this meeting, $12 \%$ of them visited a doctor thrice for the same symptoms, and $4 \%$ had visited a doctor more than three times for the same symptoms.

Table (12): The number of times the participants visited the doctor with the same symptoms prior to this visit.

\begin{tabular}{|l|l|l|}
\hline Answer & Frequency & Percent \\
\hline One & 45 & 45.0 \\
\hline Two & 39 & 39.0 \\
\hline Three & 12 & 12.0 \\
\hline More than three & 4 & 4.0 \\
\hline Total & 100 & 100.0 \\
\hline
\end{tabular}

The next table shows participants' distribution in terms of whether They been stayed in the hospital or not; $96.5 \%$ of them have not been stayed hospital, while only $3.5 \%$ were stayed hospital.

Table (13):-Participants' distribution in terms of whether they have stayed in the hospital..

\begin{tabular}{|l|l|l|}
\hline Answer & Frequency & Percent \\
\hline Yes & 20 & 3.5 \\
\hline No & 546 & 96.5 \\
\hline Total & 566 & 100.0 \\
\hline
\end{tabular}

\section{Discussion:-}

The Hajj is the largest annual gathering in the world, bringing millions of people in a small and geographically confined area together. Evidence from the literature suggests that overcrowding increases the chances of trauma and the transmission of communicable diseases. Moreover, pilgrims are subjected to fatigue and bad weather conditions during this period. Hence, crowding, fatigue and extreme climatic conditions are important factors for transmitting air- and droplet-borne infections. In fact, respiratory tract infections are one of the leading types of infections observed during the Hajj season $(7,8)$. Hence, this study aims to compare the difference between the incidence of respiratory tract infections before and after performing Hajj as well as identifying the risk factors that may increase the prevalence of respiratory tract infections during this pilgrimage.

This study includes 566 pilgrim patients of year 1437H. Most of them (92\%) suffered from respiratory symptoms, and the results of this study conform with those of Bakhsh et al., who found that most patients were suffering from respiratory problems (9). In this study, the majority of participants (71.6\%) were male. Another similarity of this study with other research is that in contrast to females, males are more prone to pneumonia infections (10). However, this finding is different from that obtained by Madani et al (11). It is somewhat illogical that most pilgrim patients are males as both genders are subjected to the same environment and physical activities during the Hajj journey.

Furthermore, we found that most patients attending the King Fahad Hospital, Al Meeqat Hospital, and Alanssar in Al Madinah belonged to the age bracket of 46-65 years old. Bakhsh et al. noted that most patients attending the Haram Medical Centre Facilities belonged to the age group of 41-60 years old (43.7\%) (12). Generally, elderly pilgrims are susceptible to infections due to exertion, lack of sleep, disturbance in dietary schedules, etc.; they develop serious medical complications due to decreased immune functions $(10,11,13,14)$.

As noted earlier, this high ratio of infection of the respiratory system is considered normal due to the extremely high crowding density to which people from many parts of the world are exposed when performing Hajj rituals. The seasonal flu vaccination, which is regarded as a preventive measure, has been recommended especially for high-risk individuals or people above 65 years old $(15,16,17)$. Besides, the recommendations for the prevention of influenza 
include wearing face masks (18). Although wearing mask may not provide complete protection from infections, it may reduce the exposure to droplet nuclei, which are considered among the main modes of transmitting most URTIs (18). We found that $32 \%$ of participants suffered from flu and $23 \%$ from a sore throat. It has been observed that the use of seasonal influenza vaccine prolongs the period of a sore throat (19). The prevalence of dry coughs (not dry coughs), high temperature, and pain in the chest was less nonetheless.

Most participants (89.2\%) had been in crowded places during the pilgrimage period. This behaviour is considered normal because of the large number of pilgrims and the limited time and space. Also, about $82.2 \%$ of the participants did not use their personal belongings during the pilgrimage period. This attitude is also considered a good indication of the awareness of pilgrims.

In our study, participants suffered from diabetes (35.7\%) and hypertension (36\%), a result which was very similar to that of Khan et al. in which 31.9\% suffered from diabetes mellitus, and 37.2\% had hypertension (20). Like the result of Emamian et al. in which $9.47 \%$ of respondents were smokers, our finding shows that $15.9 \%$ of the participants in this study were smokers (21).

The majority of our participants $(81.3 \%)$ had good ventilation in their place of residence. Such atmosphere is commendable because poor ventilation contributes to the rapid spread of infections. Besides, $63.4 \%$ of the participant's residential areas were not close to any sources of air pollution.

For the first time, approximately $82.3 \%$ of the participants visited the doctor for the same symptoms. This result means that they exhibited these respiratory symptoms during Hajj. Nonetheless, Al-Jasser et al. reported that a significant proportion (53\%) of pilgrims from Riyadh experienced a URTI during or immediately after the Hajj (18).

As in many mass gatherings, it is important to understand how to prevent the occurrence of a heavy burden of symptoms of the respiratory system. Given the circumstances of the Hajj, it is almost impossible to control the spread of illnesses facilitated by crowding adequately. The use of personal protective measures such as vaccination, chemoprophylaxis, frequent hand washing/sanitising, and face mask can provide a level of sufficient protections (22).

\section{Conclusion:-}

The recent study found that most of the patient pilgrims suffered from respiratory symptoms and that the majority of them showed these symptoms during Hajj. Regarding the risk factors which increase respiratory tract infection, most pilgrims did not use their personal belongings during the pilgrimage period. Moreover, non-smokers had a good ventilation in their place of residence, and residential places were not close to any sources of air pollution. All these factors are considered good indicators. Nevertheless, most pilgrims had been in crowded places during the pilgrimage period. Such gathering, which cannot be avoided due to a large number of people and the limited time and space, increases the chances of respiratory symptoms.

\section{Recommendation:-}

- Further studies on the same subject should include larger groups of pilgrims in various health centres in the city of Medina and Mecca.

- There should be awareness campaigns for pilgrims about the need to take proactive actions and preventive measures such as vaccination, chemoprophylaxis, frequent hand washing/sanitizing, and using face mask to provide a level of sufficient protection.

- The WHO and other global stakeholders in the health sectors should cooperate with the Saudi authorities on how to mitigate infectious diseases during Hajj.

\section{Study Strength:-}

- This study can help the world control the spread of both epidemic and pandemic diseases.

- The combination of using questionnaires and personal interviews helps increase the accuracy of the research results.

\section{Study limitations:-}

- Difficult to communicate with participants due to the language barrier.

- Poor organisation by hospitals.

Overcrowding. 


\section{Acknowledgment:}

We thank (Reem Saad Alqahtani, medical student at Taibah university), (Ghufran Muhammed A Alnaeli, medical student at Taibah university), (Abdullah Mohammed Almohammadi, medical student at Taibah university), (Meyasser Mohammed Olfat, medical student at Taibah university), (Shima Basheer Golam, medical student at Taibah university), Mohammed Adel Makkawi, Khalid Ahmad Amara and (Ala'a Saad Alrehaili, medical student at Taibah university) for assistance with data collection.

\section{References:-}

1. Ahmed QA, Arabi YM, Memish ZA. Health risks at the Hajj. Lancet (London, England) [Internet]. 2006 Mar 25 [cited 2016 Jun 16]; 367(9515):1008-15.

2. Voordouw BCG, van der Linden PD, Simonian S, van der Lei J, Sturkenboom MCJM, Stricker BHC, et al. Influenza Vaccination in Community-Dwelling Elderly. Arch Intern Med [Internet]. American Medical Association; 2003 May 12 [cited 2016 Jun 16]; 163(9):1089.

3. Gautret P, Soula G, Delmont J, Parola P, Brouqui P. Common health hazards in French pilgrims during the Hajj of 2007: a prospective cohort study. J Travel Med [Internet]. [cited 2016 Jun 28];16(6):377-81.

4. Asghar AH, Ashshi AM, Azhar EI, Bukhari SZ, Zafar TA, Momenah AM. Profile of bacterial pneumonia during Hajj. Indian J Med Res [Internet]. Medknow Publications; 2011 May [cited 2016 Jun 28]; 133(5):510-3.

5. Rashid H1, Abdul Muttalif AR, Mohamed Dahlan ZB, Djauzi S, Iqbal Z, Karim HM, Naeem SM, Tantawichien T, Zotomayor R, Patil S SH. The potential for pneumococcal vaccination in Hajj pilgrims: expert opinion. Travel Med Infect Dis [Internet]. 2013; 11(5) (288-94.):10.

6. Alzeer AH. Respiratory tract infection during Hajj. Ann Thorac Med [Internet]. Medknow Publications; 2009 Apr [cited 2016 Jun 28];4(2):50-3.

7. Madani, Tariq A., et al. "Causes of hospitalization of pilgrims during the Hajj period of the Islamic year 1423 (2003)." Annals of Saudi medicine 26.5 (2006): 346.

8. Al-Ghamdi, Saeed M., et al. "Pattern of admission to hospitals during muslim pilgrimage (Hajj)." Saudi medical journal 24.10 (2003): 1073-1076.

9. Bakhsh, Abdulrahman R., et al. "Diseases pattern among patients attending Holy Mosque (Haram) Medical Centers during Hajj 1434 (2013)." Saudi medical journal 36.8 (2015): 962.

10. Combes, Alain, et al. "Gender impact on the outcomes of critically ill patients with nosocomial infections." Critical care medicine 37.9 (2009): 2506-2511.

11. Madani, Tariq A., et al. "Causes of hospitalization of pilgrims during the Hajj period of the Islamic year 1423 (2003)." Annals of Saudi medicine 26.5 (2006): 346.

12. Bakhsh, Abdulrahman R., et al. "Diseases pattern among patients attending Holy Mosque (Haram) Medical Centers during Hajj 1434 (2013)." Saudi medical journal 36.8 (2015): 962.

13. Memish, Z. A. "The Hajj: communicable and non-communicable health hazards and current guidance for pilgrims." Euro Surveill 15.39 (2010): 19671.

14. Alzeer, A., et al. "Tuberculosis is the commonest cause of pneumonia requiring hospitalization during Hajj (pilgrimage to Makkah)." Journal of infection 36.3 (1998): 303-306.

15. Alzeer, Abdulaziz H. "Respiratory tract infection during Hajj." Annals of thoracic medicine 4.2 (2009): 50.

16. Memish, Z. A. "The Hajj: communicable and non-communicable health hazards and current guidance for pilgrims." Euro Surveill 15.39 (2010): 19671.

17. Al-Tawfiq, Jaffar A., Alimuddin Zumla, and Ziad A. Memish. "Respiratory tract infections during the annual Hajj: potential risks and mitigation strategies." Current opinion in pulmonary medicine 19.3 (2013): $192-197$.

18. Al-Jasser, Fahad S., et al. "Patterns of diseases and preventive measures among domestic hajjis from Central, Saudi Arabia." Saudi medical journal 33.8 (2012): 879-886.

19. Deris, Zakuan Zainy, et al. "The prevalence of acute respiratory symptoms and role of protective measures among Malaysian hajj pilgrims." Journal of travel medicine 17.2 (2010): 82-88.

20. Khan, Nasim A., et al. "Pattern of medical diseases and determinants of prognosis of hospitalization during 2005 Muslim pilgrimage Hajj in a tertiary care hospital. A prospective cohort study." Saudi medical journal 27.9 (2006): 1373-1380.

21. Emamian, Mohammad Hassan, Ali Mohammad Hassani, and Mansooreh Fateh. "Respiratory tract infections and its preventive measures among Hajj pilgrims, 2010: a nested case control study." International journal of preventive medicine 4.9 (2013): 1030.

22. Choudhry, A. J., et al. "Hajj-associated acute respiratory infection among hajjis from Riyadh." (2006). 